Chronic Obstructive Pulmonary Diseases:

Journal of the COPD Foundation

COPD

\title{
Review
}

\section{Neutrophil Modulation in Alpha-1 Antitrypsin Deficiency}

\author{
Elizabeth Sapey, $\mathrm{MD}^{1}$
}

\begin{abstract}
Neutrophils have been implicated in the pathogenesis of alpha-1 antitrypsin deficiency (AATD) since the first descriptions of the disease. Neutrophil proteinases can cause all lung manifestations of AATD, from small airways destruction, to emphysema, to chronic bronchitis and airflow obstruction. Initially, it was proposed that neutrophil functions were normal in AATD, responding in an initially physiological manner to a high burden of pulmonary inflammation. More recent studies have shed new light on this, describing changes in neutrophil responses (a modulation of usual cellular functions) in the presence of inflammation or infection which might enhance tissue damage while impeding bacterial clearance, providing some evidence to support there being an AATD neutrophil phenotype.

Many facets of neutrophil function in AATD can be explained by the loss of alpha-1 antitrypsin (AAT) in diverse biological processes. If this were the only reason for altered neutrophil functions, one would predict similar disease presentation across affected people. However, this is not the case. Despite similar (low) levels of AAT, lung disease is extremely variable in AATD, with some patients suffering a significant burden of lung disease and some much less, irrespective of smoking habits and, in some cases, despite augmentation therapy. This review will explore how complex neutrophil responses are and how they are altered with age, inflammation and AATD. Further, it will discuss the need to understand more completely which aspects of AATD-associated disease are driven by neutrophils and how patients more susceptible to neutrophil dysfunction could be identified to potentially stratify treatment approaches.
\end{abstract}

Abbreviations: alpha-1 antitrypsin deficiency, AATD; alpha-1 antitrypsin, AAT; neutrophil elastase, NE; proteinase 3, PR3; chronic obstructive pulmonary disease, COPD; leukotriene B4, LTB4; C-X-C chemokine receptor type 4, CXCR4; C-X-C motif chemokine 12, CXCL12; lymphocyte function-associated antigen 1, LFA-1; macrophage 1 antigen, MAC-1; nicotinamide adenine dinucleotide phosphate, NADPH; reactive oxygen species, ROS; neutrophil extracellular traps, NETs; 18 -fluorodeoxyglucose, ${ }^{\mathbf{1 8}}$ FDG; positron emission tomography-computed tomography, PET-CT; tumor necrosis factor alpha, TNFa; TNF receptor 1, TNF-R 1

Funding Support: This article was supported by an unrestricted grant from the Alpha-1 Foundation.

Date of Acceptance: January 28, 2020

Citation: Sapey E. Neutrophil modulation in alpha-1 antitrypsin deficiency. Chronic Obstr Pulm Dis. 2020;7(3):247-259. doi: https://doi. org/10.15326/jcopdf.7.3.2019.0164

1 Birmingham Acute Care Research Group, Institute of Inflammation and Ageing, University of Birmingham, Birmingham, United Kingdom

\section{Address correspondence to:}

Elizabeth Sapey, MD

Email: E.sapey@bham.ac.uk

Phone: +44121472 2000

\section{Keywords:}

alpha-1 antitrypsin deficiency; emphysema; chronic obstructive pulmonary disease; COPD; bronchitis; exacerbations; proteinases

\section{Introduction}

Alpha-1 antitrypsin (AAT) is the classical circulating anti proteinase in humans and its central function is to inhibit neutrophil proteinases (such as neutrophil elastase [NE] and proteinase 3 [PR3]). ${ }^{1}$ Such protection is warranted; neutrophil proteinases have substantial capacity to damage tissues, are able to degrade all components of the extracellular matrix and have significant effects on cell function and signaling. The actions of $\mathrm{NE}^{2-7}$ are outlined in Table 1. Proteinase 


\section{Table 1. The Actions of Neutrophil Elastase on Host Tissues}

\begin{tabular}{|c|c|}
\hline \multirow{10}{*}{$\begin{array}{l}\text { Degradation/ } \\
\text { Cleavage }\end{array}$} & Elastin \\
\hline & Collagen types I, II, III, IV, VI, VIII, IX, X, and XI Fibronectin \\
\hline & Laminin \\
\hline & Aggrecan \\
\hline & Cleaves epithelial-cadherin (E-cad), an important intercellular junction protein. \\
\hline & $\begin{array}{l}\text { Inactivates endogenous proteinase inhibitors such as a } 2 \text { antiplasmin, a1 antichymotrypsin, and tissue } \\
\text { inhibitors of metalloproteinases }\end{array}$ \\
\hline & Cleaves the hinge region of IgA \\
\hline & Cleaves complement C3bi, forming a functional opsonin mismatch \\
\hline & T lymphocyte surface antigens \\
\hline & Cleaves anti-inflammatory molecules such as sirtuin 1 which are implicated in aging \\
\hline \multirow[t]{2}{*}{ Activation } & Matrix metalloproteinase $2,3,9$ \\
\hline & Cathespin B \\
\hline \multirow{4}{*}{$\begin{array}{l}\text { Modification of } \\
\text { Inflammatory } \\
\text { Mediators }\end{array}$} & Enhances epithelial and endothelial secretion of inflammatory mediators including interleukin 8 \\
\hline & Enhances macrophage secretion of pro-inflammatory cytokines including leukoteine B4 \\
\hline & Decreases secretory leukoproteinase inhibitor (SLPI) secretion \\
\hline & Increases elafin secretion \\
\hline \multirow[t]{6}{*}{ Cell Function } & Neutrophil/ alpha-1 antitrypsin complexes are chemotactic for neutrophils \\
\hline & Cleaves intercellular adhesion molecule 1 (ICAM-1) \\
\hline & Disruption and detachment of epithelial cells \\
\hline & Reduces ciliary beating of columnar epithelium \\
\hline & $\begin{array}{l}\text { Increases MUC5 AC protein content (a gel-forming mucin that contributes to the viscoelastic properties } \\
\text { of mucus) }\end{array}$ \\
\hline & Increases cellular oxidative stress \\
\hline Cell Death & Increases epithelial and endothelial cell apoptosis \\
\hline
\end{tabular}

activity is associated with the development and progression of the many facets of chronic obstructive pulmonary disease (COPD), ${ }^{8}$ including emphysema, ${ }^{9}$ small airways damage and destruction, ${ }^{10}$ chronic bronchitis, ${ }^{11}$ acute bacterial infections and bacterial colonization. ${ }^{12,13}$ The damaging effects of neutrophil proteinases are not only felt in the lungs. These proteinases are also implicated in smoking-associated skin damage ${ }^{14}$ as well as arterial hypertension (including pulmonary arterial hypertension). ${ }^{15}$

AAT limits rather than prevents neutrophil proteinase-related damage, as it binds proteinases on a one-to-one molar basis and concentrations of NE and PR3 far exceed that of AAT at the site of a degranulating neutrophil. This leads to an area of obligate tissue damage around each degranulating cell until concentrations of the proteinases are reduced by diffusion into the local tissue environment. ${ }^{16}$ AAT preferentially binds NE rather than PR3 suggesting the obligate tissue damage caused by PR3 could exceed that of NE, ${ }^{17}$ although the disease associations of PR3 are less well studied. ${ }^{18}$

In addition to the anti-proteinase function of AAT, it is increasingly recognized that AAT has multiple nonproteinase-mediated effects, reviewed elsewhere in this series of articles. In brief, these are anti-inflammatory and immunomodulatory in nature and include reducing free radical production and associated damage, ${ }^{19-21}$ binding sterically to interleukin 8 (CXCL8) and leukotriene B4 (LTB4), reducing the signals which can initiate neutrophil migration towards inflammation ${ }^{22}$ and reducing cytokine release by macrophages, ${ }^{23}$ monocytes and neutrophils. ${ }^{24}$ AAT also has anti-microbial/viral properties, impacts on $\mathrm{T}$ and $\mathrm{B}$ cell functions ${ }^{25-27}$ and has been implicated in reducing inflammation-mediated apoptosis, including in pancreatic $B$ cells ${ }^{28}$ suggesting effects of deficiency may be far more wide- ranging than on neutrophils alone.

Alpha-1 antitrypsin deficiency (AATD) is a condition of low circulating levels of AAT, caused by mutations in SERPINA 1 and inherited in an autosomal and 
codominant pattern. Despite being considered a rare disease, AATD is relatively common, affecting between 1 in 1600 to 1 in 5000 people in screening studies, depending on geographical location. ${ }^{29,30}$ There is a wealth of data supporting the role of neutrophils, and more specifically, neutrophil proteinases in the pathogenesis of the lung diseases associated with AATD, especially those forms of AATD which have the lowest levels of circulating AAT (PiZZ and null phenotypes). Here, lung disease tends to present at a younger age than non-AATD-related COPD, and with less (and sometimes even no) cigarette smoke exposure. ${ }^{31}$ While the genetic mutations implicated in AATD are present throughout the life course of an individual, most patients with AATD are not diagnosed until middle age in the absence of specific screening. ${ }^{32}$

Lung disease is heterogeneous in AATD. In some patients, lung function is preserved and does not decline while in others, there is a rapid decline in lung function and general health. Differences in presentation and progression between PiZZ patients cannot be explained by AAT levels (which are uniformly low) or by smoking status alone. Augmentation therapy (replacement of functional AAT via an infusion) has been the main, specific treatment for AATD for many years, but this is not available globally. Furthermore, while some patients with AATD respond well to augmentation therapy, others do not appear to benefit from its effects. ${ }^{33}$ This raises an interesting question in AATD, especially in those with more severe deficiencies: if neutrophils are highly implicated in AATD-related lung disease, and AAT levels in PiZZ disease are too low to mitigate the damaging effects of neutrophil proteinases, why is disease burden so variable in its penetration? This review will explore this question, by discussing neutrophil functions in health, and how these functions may be modulated by age and with AATD to enhance tissue damage, focusing on why neutrophil-associated disease may be variably present in patients with AATD.

\section{Neutrophils in Health and Inflammation}

Neutrophils are among the first line of effector cells to be recruited in inflammation, irrespective of cause and are also the most abundant leukocyte, accounting for $70 \%$ of all circulating white blood cells. They are short-lived, with a high basal production of $1-2 \times 10^{10}$ neutrophils/day in health; increasing to approximately $10^{12}$ during inflammatory challenges. ${ }^{34}$ Their mobilization from the bone marrow is tightly controlled with neutrophil C-X-C chemokine receptor type 4 (CXCR4) and bone marrow stromal cell C-X-C motif chemokine 12 (CXCL12) interactions causing cell retention or cell return to the bone marrow and increasing surface expression of neutrophil CXCR2 causing neutrophil release into the circulation. ${ }^{35,36}$ Once in the circulation, neutrophils are able to navigate towards the source of inflammation using only small gradients in inflammatory cytokines. They do this through internal amplification of signals via positive feedback loops, with cell polarization (a clear "front" and "back" morphology, facing the inflammatory source) central to this process. ${ }^{37}$ To enable migration through dense extracellular matrices, neutrophils utilize granules containing high concentrations of proteinases such as NE and PR3. NE and PR3 have significant proteolytic activity and the radius of tissue damage is up to 8 times greater than that of the granule itself for $\mathrm{NE}^{38}$ and even more for PR $3^{18}$ due to quantum proteolysis and AAT enzyme kinetics, leaving an obligate trail of damaged tissue. Once at the site of inflammation, neutrophils are avid and unrestricted phagocytes, engulfing tissue debris, pathogens and damaged cells, but also recruit other neutrophils to the source of inflammation while phagocytosis is still required. They form dense cellular clusters or "swarms" of cells in the presence of LTB4, with the swarms maintained through auto and paracrine amplification of LTB4 secretion. Swarm size (and thus the potential for bystander tissue damage) is contained/ limited by repeated neutrophil to neutrophil contact through 2 main integrins; lymphocyte function-associated antigen 1 (LFA-1) and macrophage 1 antigen (MAC1) interactions. The combination of localized LTB4 and close cell contact through integrins appears to both drive swarm formation but also limit the size of the swarm, to prevent local tissue damage beyond the inflamed tissue. ${ }^{39}$

In overwhelming infection or inflammation, neutrophils can release their granule contents extracellularly, and primary and secondary granules contain a wealth of bacteriocidal proteins including myeloperoxidase, proteinases, defensins and nicotinamide adenine dinucleotide phosphate (NADPH) oxidase which form reactive oxygen species (ROSs). ${ }^{40}$ ROSs have antimicrobial activity but also 
are utilized in cellular signaling and in the formation of neutrophil extracellular traps (NETs), which are able to entrap bacteria in a net which is significantly larger than the cell, exposing bacteria to high concentrations of antimicrobial peptides. ${ }^{41}$ Degranulation, NETosis and $R O S$ release have all been associated with tissue damage, and so to limit the potential for unwarranted neutrophil activity, neutrophils exist in 3 states, quiescent, primed and activated, with the ability to move between states, depending on the environment. ${ }^{42}$ Of note, recent elegant studies suggest that the narrow and tortuous pulmonary capillary bed might act as a venue for neutrophil depriming. Here, the mechanical manipulation of neutrophils through narrow vessels appears to assist with the cell entering a more quiescent state. ${ }^{43,44}$ This suggests a healthy lung environment is needed for adequate cell de-priming to occur.

\section{Neutrophil Maturity and Phenotype}

Circulating neutrophil numbers are not constant throughout the day. Neutrophils are released from the bone marrow during the resting phase of an animal's life (night, for most humans), with absolute numbers peaking at this time. Aged neutrophils are then cleared before the waking phase of the day, ${ }^{45}$ expressing more CXCR4 and migrating to areas of higher concentrations of CXCL12 (including the bone marrow) which are cleared following apoptosis. ${ }^{46}$ There is some evidence that neutrophil function changes as the cells age with more aged cells having an increased capacity to phagocytoze bacteria ${ }^{47}$ and to produce more NETs and $\mathrm{ROSs}^{48}$ but this requires further study.

To add to this complex picture, it is increasingly recognized that neutrophils may be more heterogenous in functional responses than previously appreciated. Neutrophils are transcriptionally active 49 and experimental models have described an increasing number of neutrophil phenotypes which have different functional characteristics. Studies have described anti-inflammatory neutrophils, involved in tumor clearance $^{50}$ and dampening of $\mathrm{T}$ cell responses via MAC1 signaling. ${ }^{51}$ A subset have been shown to reverse transmigrate back into the systemic circulation $^{52}$ and there also appears to be a proangiogenic neutrophil, ${ }^{53}$ characterized by increased MMP-9 release. ${ }^{54,55}$ This has been reviewed recently. ${ }^{56}$

\section{Host Aging and Neutrophil Responses}

As well as potential changes in function as the neutrophil ages, there are also changes in neutrophil function as the host ages, and as AATD is a genetic condition, this may have relevance in disease pathogenesis across the life course. In healthy infants, isolated neutrophils have been shown to display reduced migratory accuracy, ${ }^{57}$ reduced degranulation in the presence of a stimulus, ${ }^{58}$ preserved phagocytosis 59 and preserved ROS generation ${ }^{60}$ but reduced NET generation ${ }^{61}$ compared to young adults. There are also changes in neutrophil function at the other extreme of age, with old age associated with impaired migration due to dysregulated and excessive PI3K activity, ${ }^{62}$ reduced NET generation, ${ }^{63}$ reduced phagocytosis ${ }^{64-66}$ and increased spontaneous ROS production ${ }^{67}$ but decreased ROS production following stimulation. ${ }^{68}$ These changes in function (especially those associated with host aging) could predispose towards less effective pathogen clearance but increased bystander tissue damage, and these deficits may be compounded even more during severe infections. Usually, the combination of inflammation and hypoxia prolongs the lifespan of neutrophils, priming and activating them to initiate pathogen clearance. ${ }^{69}$ In sepsis, especially in the very young and very old, neutrophil function is globally reduced, a state which appears to persist long term. ${ }^{70-72}$ Furthermore, there is an increased incidence of neutropenia during infection due to blunted responses to granulocyte colony stimulating factor $(\mathrm{G}-\mathrm{CSF})^{73}$ resulting in both a reduction in cell mobilization from the bone marrow without an increase in the survival of activated and mature cells. However, in some instances these functions appear rescuable, offering the potential for therapeutic manipulation. ${ }^{74,75}$

Hence, a number of factors might impact neutrophil function; the age of the neutrophil, the age of the host, the state of the neutrophil (activated, primed or quiescent) and potentially the phenotype of the neutrophil (classical, pro-angiogenic, antiinflammatory) before one considers the impact of disease. 


\section{Neutrophilic Inflammation and Neutrophil Functions in Alpha-1 Antitrypsin Deficiency}

Airway neutrophilia is a feature of $\operatorname{AATD}^{76}$ but this could reflect the inflammatory environment of the lung, an intrinsic difference in how the cell functions (a modulation of function), or a combination of both.

Studies which have sampled the lungs of patients with AATD describe significant inflammation, and sputum from patients with AATD is highly chemotactic, with increased levels of the neutrophil chemoattractants CXCL8 and LTB4 and high neutrophil counts ${ }^{77}$ suggesting these cells are responding to the these chemoattractants by passing from blood into the airways, although (as in usual $\mathrm{COPD}^{78}$ ) levels vary between even quite closely matched PiZZ patients. ${ }^{79}$ However, studies have focused on individuals with impaired lung function, and there is little in the literature to describe the lung environment of those without significant lung disease or younger patients. This significantly lessens our understanding of what might be the initiating damaging signals in AATD lung disease. It is known that the presence of inflammation affects cell functions ${ }^{80}$ and chronic inflammation is likely to have long term impact on the local environment, amplifying the complex inflammatory milieu through a number of mechanisms including epigenetic change. ${ }^{81}$ In established disease it is difficult to identify AATD-specific changes versus those present due to chronic inflammation. A study of end-stage AATD patients compared to end stage non-AATD COPD highlights this, assessing host lung samples from 2 groups of patients at transplant. There were no differences in cellular studies between the upper or lower zones of the lung, despite differing locations of emphysema, potentially questioning the contribution of chronic inflammation versus disease specific pathology. ${ }^{82}$ A birth cohort of screened AATD patients and control participants suggested no abnormalities in lung function were present in any of the 16 year olds screened, ${ }^{83}$ but by the time the same cohort had reached 22 years of age, approximately $14 \%$ of the AATD patients had chronic bronchitis and exertional dyspnea and most had a decline in lung function that was above the expected for health. ${ }^{84}$ Furthermore, most individuals had evidence of small airways dysfunction and apical emphysema (evidenced by reduced lung density) in their late thirties ${ }^{85}$ all of which can be consequences of increased neutrophil activity although inflammation was not studied in these studies.

The increased ability of AATD neutrophils to migrate towards AATD sputum does not just reflect the increased chemoattractant burden but is amplified by the lack of functional AAT. AAT can deter excessive neutrophil recruitment both by binding directly to CXCL8, preventing CXCL8 binding to CXCR1 on neutrophils and by preventing ADAM17: Fc receptor FcyRIIIb interactions on the surface of neutrophils, which would normally initiate downstream chemotaxis signaling events. ${ }^{86}$ The increased levels of LTB4 would lead to an increased tendency of AATD neutrophils to "swarm" within inflamed tissues. However, neutrophil proteinases can cleave LFA-1 and MAC1, ${ }^{87,88}$ (required to limit swarm size) and in the presence of AATD, the combination of both enhanced LTB4 and reduced integrin interactions could lead to uncontained neutrophil swarming, and significant tissue damage. Since migration is associated with proteinase and ROS release, the swarming cells would cause more obligate tissue damage and more LTB4 release, in a vicious cycle of injury, irrespective of the initiating cause. In keeping with this, there is clear evidence of increased neutrophil proteinase activity in AATD, with footprints of both NE and PR3 present systemically, with relationships with proteinase burden and disease severity, 89,90 even in never smoking individuals. There is also an increased burden of ROSs in AATD, and AAT modulates neutrophil ROS production elicited by $\mathrm{N}$-formylmethionine-leucyl-phenylalanine and CXCL8 in a dose dependant manner. ${ }^{20}$

Phagocytosis appears to be reduced in AATD, with a number of studies showing a reduced ability of AATD neutrophils to engulf different pathogens including non-typeable haemophilus influenzae, ${ }^{91}$ a bacteria of particular significance in lung disease. There are few studies of NET formation in AATD. One study using the non-physiological stimulant phorbol myristate acetate described that NET formation was not altered in AATD, however, this study is yet to be replicated using disease relevant stimuli. ${ }^{92}$ Finally, studies have described accelerated neutrophil apoptosis in AATD. ${ }^{93}$

In total, this would support an aggressive neutrophil phenotype in AATD but one with limited capacity to clear bacteria, and this would be in keeping with the neutrophil-associated lung damage present in AATD 
and the high numbers of exacerbations experienced by some within this patient group. The damaged lung tissue present in so many patients with AATD may make any functional activation of neutrophils worse, as the damage to the pulmonary capillary network may impede de-priming, creating a vicious cycle of disease. Figure 1 provides a visual overview of these processes.

However, it would be too simple to assume that the burden of disease in AATD merely reflected increased neutrophil activity. The 18-fluorodeoxyglucose ( ${ }^{18} \mathrm{FDG}$ ) positron emission tomography-computed tomography (PET-CT) studies provide data of pulmonary glucose uptake, which has been shown to relate to neutrophil activity in animal models. ${ }^{94,95}$ PET-CT scans of patients with COPD have shown ${ }^{18}$ FDG uptake which was greater in emphysematous regions of the lung, and correlated with physiological measures of disease severity. ${ }^{96}$ However, in AATD, pulmonary ${ }^{18}$ FDG uptake was similar to healthy controls, which did not support an active neutrophil signal in AATD emphysematous regions of the lung. The reasons for this are unclear, but may reflect the emphysema being now "burned out," with less cell activity than would have been seen in an early disease, differences in neutrophil activity in AATD and nonAATD related emphysema, or that neutrophilic inflammation was not the driver of disease in this subset of patients. This has yet to be confirmed, but initial studies suggest there are functional differences in non-AATD COPD and AATD neutrophils, including less accurate migration in non-AATD COPD. ${ }^{8}$ What is clear is that neutrophils in AATD are not merely "activated" (or their survival would be enhanced) or "older cells" (or their phagocytosis would be preserved), or cells from an older host (or their ROS production during a challenge would be blunted).

\section{Figure 1. Interactions Between Alpha-1 Antitrypsin Deficiency, Lung Disease and Neutrophil Functions}

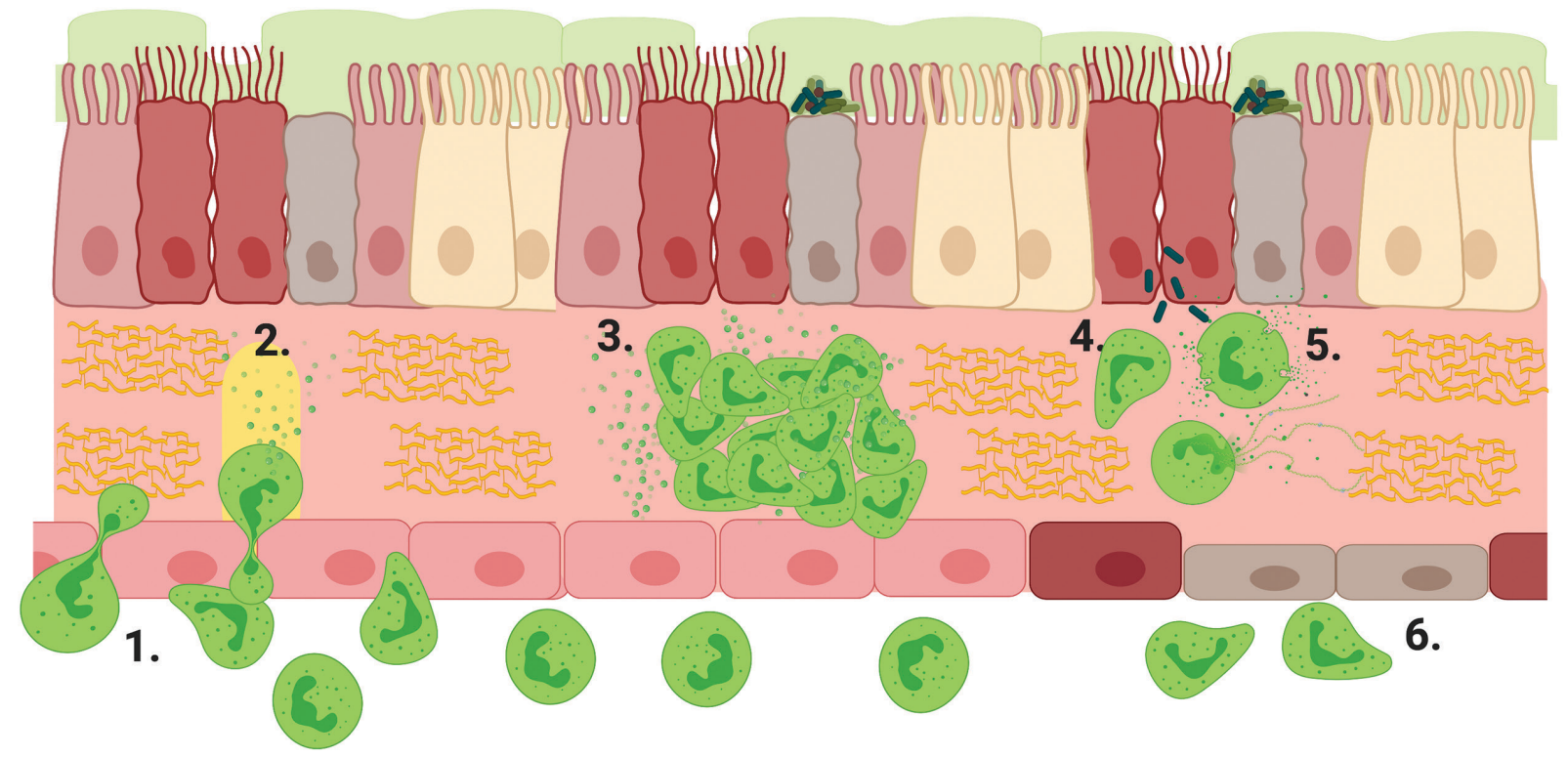

AAT has multiple effects on neutrophils and the inflammatory lung environment which, when deficient, could enhance lung disease. 1. The AATD lung environment is highly chemotactic to neutrophils, with raised concentrations of chemokines including CXCL8 and LTB4 causing cell priming and activation and increasing their recruitment.

2. Migration is associated with a release of proteinases and ROS, to enable movement through complex tissues, leading to obligate tissue damage which cannot be easily contained, due to low AAT levels.

3. High levels of LTB4 could induce neutrophil swarming while proteinase-associated cleavage of integrin receptors could prevent containment of that swarm, again increasing the area of tissue damage.

4. Proteinase cleavage of complement and immunoglobulins lead to failure of opsonophagocytosis, impeding bacterial clearance.

5. Increased ROS release supplements the inflammatory locale.

6. Local pulmonary capillary damage prevents the depriming of neutrophils, so activated cells are present systemically.

AAT=alpha-1 antitrypsin; AATD=alpha-1 antitrypsin deficiency; LTB4=leukotriene B4; ROS=reactive oxygen species 


\section{Impacts of Treatment}

There is evidence that augmentation therapy can restore or improve some aspects of neutrophil function, supporting the suggestion that at least some aspects of neutrophil dysfunction are directly related to low functional levels of AAT. These include augmentation causing increased AAT binding to CXCL-8 and the neutrophil membrane, decreased FcyRIIIb release from the neutrophil membrane and reducing CXCL8: CXCR1 interactions, with normalization of chemotaxis. ${ }^{86}$ Augmentation therapy has also been associated with a reduction in systemic and pulmonary cytokines, including tumor necrosis factor alpha (TNFa) and LTB4 (which might theoretically limit swarming), an improvement in bacterial killing and a reduction in cellular apoptosis. ${ }^{93}$ In keeping with this, augmentation therapy has been associated with a reduction in systemic PR3 activity, with this falling from $287 \mathrm{nM}$ to $48.6 \mathrm{nM}$ in a recent study. ${ }^{89}$ Not all neutrophil functions have been tested to date, and it is unclear whether treatment with augmentation merely corrects the proteinase/antiproteinase balance in the immediate environment or has a more profound effect on neutrophil function or phenotype.

\section{Potential Drivers of Functional Change}

What none of the available studies have been able to address so far is why there is such variability in disease burden in AATD, even within never smoking PiZZ patients. There is evidence that neutrophil functions associated with disease vary significantly between AATD patients, and this might in part explain some differences in disease presentation, with some patients having highly injurious neutrophil activity and some less so. For example, in studies of a neutrophil elastase activity footprint, there was a 3.75 fold difference between the highest and lowest NE activity levels between patients with severe AATD deficiency. ${ }^{97}$ Similarly, in a recent study, the PR3 activity footprint showed an 18-fold difference between the highest and lowest values in patients with PiZZ AATD. ${ }^{89}$ The reasons for this are unclear, as little is known about the variability of neutrophil proteinase release and activity in health, or with age. However, in the prementioned studies, the differences in proteinase activity could not fully explain lung disease severity, rates of decline or be attributed to smoking status. It might be that those with the greatest level of proteinase activity also suffer the most inflammatory burden but understanding which came first (the inflammation or the change in neutrophil function) will be challenging. Furthermore, most studies of AATD have focused on systemic cells and neutrophils from the lung compartment may differ in response and require study.

There may be other reasons why lung disease penetration is so variable in AATD. Lifestyle is obviously important, and it has been known for many years that smoking cigarettes with AATD accelerates lung disease, just as a high burden of cigarette exposure is an important risk factor for non-AATD COPD.

Age is a risk factor for lung disease in AATD 98 and many patients with AATD survive to an older age, making it important to understand the impact of AATD in old age. Most studies of older adults describe low-grade, systemic inflammation including in proinflammatory cytokines such as interleukin 6 and TNFa. ${ }^{99}$ TNFa is especially important in AATD, as AAT inhibits TNFa converting enzyme (TACE; ADAM17) activity and TNF receptor 1 (TNF-R 1 ) expression, reducing the conversion of pro-TNF to soluble TNFa, preventing the self-propagating autocrine signaling of the secreted TNF-a. ${ }^{80}$ How we age is extremely heterogeneous, with huge variations in the presence of the hallmarks of cellular and tissue aging (which are genomic instability, telomere attrition, epigenetic alterations and loss of proteostasis) ${ }^{100}$ and it might be that the presentation of AATD is a reflection of our overall ability to age well. In keeping with this, it is increasingly recognized that patients with AATD frequently have other diseases (multimorbidity or 2 or more conditions in the same individual) and potentially these may influence general health and lung function, by increasing inflammatory burden or altering immune cell function. There is huge interest in trying to identify both factors of susceptibility and resilience to chronic disease to provide mechanistic insight which could be therapeutically targeted, but these are likely to be highly complex, reflecting both genetic and environmental interactions. ${ }^{101}$ Such genetic and environmental factors may also impact on neutrophil function in AATD. Emerging studies are already identifying the impact of epigenetic modifications in neutrophils, and these long-lived changes in cellular function have been shown to impact on inflammatory pathways and signals. ${ }^{102}$ These studies will need to be 
expanded upon, to fully understand the place of this complex cell in a complex disease.

Finally, not all patients with AATD may have active neutrophilic inflammation as a predominant signal, and inflammatory studies using lung and systemic samples would help stratify patients so that treatments could be better targeted.

\section{Conclusions}

For years the central role of neutrophils and neutrophil proteinases have been described in AATD pathogenesis, and there is increasing evidence of neutrophil dysfunction in AATD, a modulation of the classically described neutrophil functions, which could contribute to the burden of disease for many patients. However, this has been a challenging area of study. Neutrophils are short-lived, difficult to genetically modify and quick to activate when manipulated or removed from their host environment. Furthermore, neutrophil function is likely to change within the compartment where the cell is sampled (bone marrow, blood, lung) and sample collection can be invasive. However, studies to date suggest that the combination of a lack of AAT, lung damage and inflammation is likely to be associated with a particularly aggressive (in terms of tissue damage) but ineffective (in terms of bacterial clearance) neutrophil phenotype. However, neutrophil responses are complex, reflecting the age of the cell, the age of the host, the potential phenotype of the cell and the chronic inflammatory environment the cell is in.

We have a sound understanding of the impact of neutrophil inflammation and proteinases in experimental models, which relate to the clinical manifestations of AATD. However, it is increasingly clear that AATD is a complex disease, with heterogeneity in disease onset, pathology and progression and a mechanistic understanding of why some patients develop severe (or no) lung disease is vital. Identifying which patients have disease driven by neutrophils will allow us to stratify our therapeutic approach, both for augmentation therapy with AAT and beyond. This is especially timely now, as proteinase inhibitors are under assessment in AATD. Being able to select the patients most likely to benefit from neutrophil-based therapeutics will be critical if these therapies are to progress into clinical practice. However, even in those patients, caution is needed, so as to normalize, and not inhibit a biological system so crucial to host defense. ${ }^{103}$ If we are able to achieve this, not only will AATD patients benefit, but so will many other people with chronic illnesses which are driven by excessive or ill-targeted neutrophil responses.

\section{Declaration of Interest}

Dr Sapey reports grants from the Alpha-1 Foundation, Wellcome Trust, Medical Research Council, British Lung Foundation and the National Institute of Health Research. She has no other conflicts of interest. 


\section{References}

1. Jacobsson KI. Studies on the determination of fibrinogen in human blood plasma. II. Studies on the trypsin and plasmin inhibitors in human blood serum. Scand J Clin Lab Invest.1955;7:3-102.

2. Drew W, Wilson DV, Sapey E. Inflammation and neutrophil immunosenescence in health and disease: Targeted treatments to improve clinical outcomes in the elderly. Exp Gerontol. 2018;105:70-77. doi: https://doi.org/10.1016/j.exger.2017.12.020

3. Brezski RJ, Jordan RE. Cleavage of IgGs by proteases associated with invasive diseases: An evasion tactic against host immunity? $m A$ Abs 2010;2(3):212-220.

doi: https://doi.org/10.4161/mabs.2.3.11780

4. Butler A, Walton GM, Sapey E. Neutrophilic inflammation in the pathogenesis of chronic obstructive pulmonary disease. COPD. 2018;15(4):1-13.

5. Joslin G, Griffin GL, August AM, et al. The serpin-enzyme complex (SEC) receptor mediates the neutrophil chemotactic effect of alpha-1 antitrypsin-elastase complexes and amyloidbeta peptide. J Clin Invest. 1992;90(3):1150-1154.

doi: https://doi.org/10.1172/JCI115934

6. Boxio R, Wartelle J, Nawrocki-Raby B, et al. Neutrophil elastase cleaves epithelial cadherin in acutely injured lung epithelium. Respir Res. 2016;7:129.

doi: https://doi.org/10.1186/s12931-016-0449-x

7. Lee K-H, Jeong J, Koo Y-J, Jang A-H, Lee C-H, Yoo C-G. Exogenous neutrophil elastase enters bronchial epithelial cells and suppresses cigarette smoke extract-induced heme oxygenase-1 by cleaving sirtuin 1. J Biologic Chem. 2017;292:1970-11979.

doi: https://doi.org/10.1074/jbc.M116.771089

8. Sapey E, Stockley JA, Greenwood H, et al. Behavioral and structural differences in migrating peripheral neutrophils from patients with chronic obstructive pulmonary disease. Am J Respir Crit Care Med. 2011;183(9):1176-1186. doi: https://doi.org/10.1164/rccm.201008-1285OC

9. Shapiro SD, Goldstein NM, Houghton AM, Kobayashi DK, Kelley D, Belaaouaj A. Neutrophil elastase contributes to cigarette smoke-induced emphysema in mice. Am J Pathol. 2003;163(6):2329-2335.

doi: https://doi.org/10.1016/S0002-9440(10)63589-4

10. Madge N, Donnelly L, Rogers D. Neutrophil elastase contributes to activated human neutrophil-induced rat small airway dysfunction. Eur Respir J .2015;46(Suppl59):PA913. doi: https://doi.org/10.1183/13993003.congress-2015.PA913

11. Voynow JA, Fischer BM, Malarkey DE, et al. Neutrophil elastase induces mucus cell metaplasia in mouse lung. Am J Physiol Lung Cell Mol Physiol. 2004;287(6): L1293-L1302. doi: https://doi.org/10.1152/ajplung.00140.2004
12. Delacourt C, Hérigault S, Delclaux C, et al. Protection against acute lung injury by intravenous or intratracheal pretreatment with EPI-HNE-4, a new potent neutrophil elastase inhibitor. Am J Respir Cell Mol Biol. 2002;26(3):290-297. doi: https://doi.org/10.1165/ajrcmb.26.3.4611

13. Thulborn SJ, Mistry V, Brightling CE, Moffitt KL, Ribeiro D, Bafadhel M. Neutrophil elastase as a biomarker for bacterial infection in COPD. Respir Res. 2019;20:170. doi: https://doi.org/10.1186/s12931-019-1145-4

14. Rijken F, Bruijnzeel PLB. The pathogenesis of photoaging: the role of neutrophils and neutrophil-derived enzymes. J Investig Dermatol Symp Proc. 2009;14(1):67-72. doi: https://doi.org/10.1038/jidsymp.2009.15

15. Taylor S, Dirir O, Zamanian RT, Rabinovitch M, Thompson AAR. The role of neutrophils and neutrophil elastase in pulmonary arterial hypertension. Front Med. 2018;5: 217. doi: https://doi.org/10.3389/fmed.2018.00217

16. Campbell EJ, Campbell MA, Boukedes SS, Owen CA. Quantum proteolysis by neutrophils; implications for pulmonary emphysema in alpha-1 antitrypsin deficiency. J Clin Invest.1999;104:337-344. doi: https://doi.org/10.1172/JCI6092

17. Sinden NJ, Baker MJ, Smith DJ, Kreft J-U, Dafforn TR, Stockley RA. a-1-antitrypsin variants and the proteinase/antiproteinase imbalance in chronic obstructive pulmonary disease. Am J Physiol Lung Cell Mol Physiol. 2015;308(2):L179-L190.

doi: https://doi.org/10.1152/ajplung.00179.2014

18. Crisford H, Sapey E, Stockley RA. Proteinase 3; a potential target in chronic obstructive pulmonary disease and other chronic inflammatory diseases. Respir Res. 2018; 19:180. doi: https://doi.org/10.1186/s12931-018-0883-z

19. Bucurenci N, Blake DR, Chidwick K, Winyard PG. Inhibition of neutrophil superoxide production by human plasma a1antitrypsin. FEBS Letters. 1992;300:21-24. doi: https://doi.org/10.1016/0014-5793(92)80156-B

20. Alfawaz B, Bergin DA, McElvaney NG, Reeves EP. Alpha-1 antitrypsin regulates neutrophil reactive oxygen species production via inhibition of key players of the respiratory burst oxidase system. BMC Proceedings. 2013;7:P7-P7. doi: https://doi.org/10.1186/1753-6561-7-S1-P7

21. Janciauskiene S, Tumpara S, Wiese M, et al. Alpha-1 antitrypsin binds hemin and prevents oxidative activation of human neutrophils: putative pathophysiological significance. $J$ Leukoc Biol. 2017;102:1127-1141.

doi: https://doi.org/10.1189/jlb.3A0317-124R

22. Lomas DA, Stone SR, Llewellyn-Jones C, Keogan MT, Wang ZM, Rubin $\mathrm{H}$. The control of neutrophil chemotaxis by inhibitors of cathepsin G and chymotrypsin. J Biol Chem. 1996;270:2343723443. doi: https://doi.org/10.1074/jbc.270.40.23437 
23. Churg A, Wang X, Wang RD, Meixner SC, Pryzdial ELG, Wright JL. a1-antitrypsin suppresses TNF-a and MMP-12 production by cigarette smoke-stimulated macrophages. Am J Respir Cell Mol Biol. 2007;37(2):144-151.

doi: https://doi.org/10.1165/rcmb.2006-0345OC

24. Nita I, Hollander C, Westin U, Janciauskiene S-M. Prolastin, a pharmaceutical preparation of purified human alpha-1 antitrypsin, blocks endotoxin-mediated cytokine release. Respir Res. 2005;6:12. doi: https://doi.org/10.1186/1465-9921-6-12

25. Cantin AM,Woods DE. Aerosolized prolastin suppresses bacterial proliferation in a model of chronic pseudomonas aeruginosa lung infection. Am J Respir Crit Care Med. 1999;160(4):11301135. doi: https://doi.org/10.1164/ajrccm.160.4.9807166

26. Zhou X, Liu Z, Zhang J, Adelsberger JW, Yang J, Burton GF. Alpha-1 antitrypsin interacts with gp41 to block HIV-1 entry into CD4+ T lymphocytes. BMC Microbiol. 2016;16:172. doi: https://doi.org/10.1186/s 12866-016-0751-2

27. Gupta J, Chattopadhaya D, Bhadoria DP, et al. T lymphocyte subset profile and serum alpha-1 antitrypsin in pathogenesis of chronic obstructive pulmonary disease. Clin Exp Immunol. 2007;149(3):463-469.

doi: https://doi.org/10.1111/j.1365-2249.2007.03429.x

28. Zhang B, Lu Y, Campbell-Thompson M, et al. a1-antitrypsin protects $\beta$-cells from apoptosis. Diabetes. 2007;56(5):1316. doi: https://doi.org/10.2337/db06-1273

29. Sveger T. Liver disease in alpha-1 antitrypsin deficiency detected by screening of 200,000 infants. New Eng J Med. 1976;294:13161321. doi: https://doi.org/10.1056/NEJM197606102942404

30. O’Brien ML, Buist NRM, Murphey WH. Neonatal screening for alpha<sub>1</sub>-antitrypsin deficiency. $J$ Pediatr. 1978;92:1006-1010.

doi: https://doi.org/10.1016/S0022-3476(78)80388-6

31. Stockley JA, Ismail AM, Hughes SM, Edgar R, Stockley RA, Sapey E. Maximal mid-expiratory flow detects early lung disease in alpha1-antitrypsin deficiency. Eur Respir J. 2017; 49(3):1-10. doi: https://doi.org/10.1183/13993003.02055-2016

32. Campos MA, Wanner A, Zhang G, Sandhaus RA. Trends in the diagnosis of symptomatic patients with alpha-1 antitrypsin deficiency between 1968 and 2003. Chest. 2005;128(3):1179-1186. doi: https://doi.org/10.1378/chest.128.3.1179

33. Balbi B, Ferrarotti I, Miravitlles M. Efficacy of augmentation therapy for emphysema associated with a-1 antitrypsin deficiency: enough is enough. Eur Respir J. 2016;47(1):35. doi: https://doi.org/10.1183/13993003.01145-2015

34. Summers C, Rankin SM, Condliffe AM, Singh N, Peters AM, Chilvers ER. Neutrophil kinetics in health and disease. Trends Immunol. 2010;31(8):318-324.

doi: https://doi.org/10.1016/j.it.2010.05.006
35. Kolaczkowska E, Kubes P. Neutrophil recruitment and function in health and inflammation. Nat Rev Immunol. 2013;13:159-175. doi: https://doi.org/10.1038/nri3399

36. Eash KJ, Greenbaum AM, Gopalan PK, Link DC. CXCR2 and CXCR4 antagonistically regulate neutrophil trafficking from murine bone marrow. J Clin Invest. 2010;120(7):2423-2431. doi: https://doi.org/10.1172/JCI41649

37. Németh T, Mócsai A. Feedback amplification of neutrophil function. Trends Immunol. 2016;37(6):412-424. doi: https://doi.org/10.1016/j.it.2016.04.002

38. Liou TG, Campbell EJ. Quantum proteolysis resulting from release of single granules by human neutrophils: a novel, nonoxidative mechanism of extracellular proteolytic activity. $J$ Immunol. 1996;157:2624-2631.

39. Lämmermann T, Afonso PV, Angermann BR, et al. Neutrophil swarms require LTB4 and integrins at sites of cell death in vivo. Nature. 2013;498:371-375. doi: https://doi.org/10.1038/nature12175

40. Amulic B, Cazalet C, Hayes GL, Metzler KD, Zychlinsky A. neutrophil function: from mechanisms to disease. Annu Rev Immunol. 2012;30:459-489.

doi: https://doi.org/10.1146/annurev-immunol-020711-074942 Brinkmann V, Zychlinsky A. Neutrophil extracellular traps: is immunity the second function of chromatin? J Cell Biol;198(5):773.

doi: https://doi.org/10.1083/jcb.201203170

41. Brinkmann V, Zychlinsky A. Neutrophil extracellular traps: is immunity the second function of chromatin? J Cell Biol. 198(5):773. doi: https://doi.org/10.1083/jcb.201203170

42. Sapey E, Stockley RA. Red, amber and green: the role of the lung in de-priming active systemic neutrophils. Thorax. 2014;69(7):606-608.

doi: https://doi.org/10.1136/thoraxjnl-2014-205438

43. Ekpenyong AE, Toepfner N, Fiddler C, et al. Mechanical deformation induces depolarization of neutrophils. Sci Adv. 2017; 3:e1602536.

doi: https://doi.org/10.1126/sciadv.1602536

44. Vogt KL, Summers C, Chilvers E, M Condliffe A. Priming and de-priming of neutrophil responses in vitro and in vivo. Eur $J$ Clin Invest. 2018;48(S2):e12967. doi: https://doi.org/10.1111/eci.12967

45. Casanova-Acebes M, Pitaval C, Weiss LA, e tal. Rhythmic modulation of the hematopoietic niche through neutrophil clearance. Cell. 2013;153(5):1025-1035. doi: https://doi.org/10.1016/j.cell.2013.04.040

46. Martin C, Burdon PCE, Bridger G, et al. Chemokines acting via CXCR2 and CXCR4 control the release of neutrophils from the bone marrow and their return following senescence. Immunity. 2003;19(4):583-593.

doi: https://doi.org/10.1016/S1074-7613(03)00263-2 
47. Uhl B, Vadlau Y, Zuchtriegel G, et al. Aged neutrophils contribute to the first line of defense in the acute inflammatory response. Blood. 2016;128(19):2327-2337. doi: https://doi.org/10.1182/blood-2016-05-718999

48. Zhang D, Chen G, Manwani D, et al. Neutrophil ageing is regulated by the microbiome. Nature. 2015;525:528-532. doi: https://doi.org/10.1038/nature15367

49. Yost CC, Denis MM, Lindemann S, et al. Activated polymorphonuclear leukocytes rapidly synthesize retinoic acid receptor-a. J Exp Med. 2004;200(5):671.

doi: https://doi.org/10.1084/jem.20040224

50. Sagiv Jitka Y, Michaeli J, Assi S, et al. Phenotypic diversity and plasticity in circulating neutrophil subpopulations in cancer. Cell Reports. 2015;10(4):562-573.

doi: https://doi.org/10.1016/j.celrep.2014.12.039

51. Pillay J, Kamp VM, van Hoffen E, et al. A subset of neutrophils in human systemic inflammation inhibits $\mathrm{T}$ cell responses through Mac-1. J Clin Invest. 2012;122(1):327-336. doi: https://doi.org/10.1172/JCI57990

52. Buckley CD, Ross EA, McGettrick HM, et al. Identification of a phenotypically and functionally distinct population of longlived neutrophils in a model of reverse endothelial migration. $J$ Leukoc Biol. 2006;79(2):303-311. doi: https://doi.org/10.1189/jlb.0905496

53. Bekes EM, Schweighofer B, Kupriyanova TA, Tumor-recruited neutrophils and neutrophil TIMP-free MMP-9 regulate coordinately the levels of tumor angiogenesis and efficiency of malignant cell intravasation. Am J Pathol. 2011;179(3):14551470. doi: https://doi.org/10.1016/j.ajpath.2011.05.031

54. Christoffersson G, Vågesjö E, Vandooren J, et al.VEGF-A recruits a proangiogenic MMP-9-delivering neutrophil subset that induces angiogenesis in transplanted hypoxic tissue. Blood. 2012;120(23):4653.

doi: https://doi.org/10.1182/blood-2012-04-421040

55. Massena S, Christoffersson G, Vågesjö E, et al. Identification and characterization of VEGF-A-responsive neutrophils expressing CD49d, VEGFR1, and CXCR4 in mice and humans. Blood. 2015;126(17):2016-2056.

doi: https://doi.org/10.1182/blood-2015-03-631572

56. Hughes MJ, Sapey E, Stockley R. Neutrophil phenotypes in chronic lung disease. Expert Rev Respir Med. 2019;13(10):951967. doi: https://doi.org/10.1080/17476348.2019.1654377

57. Weinberger B, Laskin DL, Mariano TM, et al. Mechanisms underlying reduced responsiveness of neonatal neutrophils to distinct chemoattractants. J Leukoc Biol. 2001;70:969-976.
58. Levy O, Martin S, Eichenwald E, et al. Impaired innate immunity in the newborn: newborn neutrophils are deficient in bactericidal/ permeability-increasing protein. Pediatrics. 1999;104(6):13271333. doi: https://doi.org/10.1542/peds.104.6.1327

59. Makoni M, Eckert J, Anne Pereira H, Nizet V, Lawrence SM. Alterations in neonatal neutrophil function attributable to increased immature forms. Early Hum Dev. 2016;103:1-7. doi: https://doi.org/10.1016/j.earlhumdev.2016.05.016

60. Bektas S, Goetze B, Speer CP. Decreased adherence, chemotaxis and phagocytic activities of neutrophils from preterm neonates. Acta Paediatr Scand.1990;79(11):1031-1038. doi: https://doi.org/10.1111/j.1651-2227.1990.tb11379.x

61. Yost CC, Cody MJ, Harris ES, et al. Impaired neutrophil extracellular trap (NET) formation: a novel innate immune deficiency of human neonates. Blood. 2009;113(25):6419. doi: https://doi.org/10.1182/blood-2008-07-171629

62. Sapey E, Greenwood H, Walton G, et al. Phosphoinositide 3-kinase inhibition restores neutrophil accuracy in the elderly: toward targeted treatments for immunosenescence. Blood. 2014;123(2):239-248.

doi: https://doi.org/10.1182/blood-2013-08-519520

63. Hazeldine J, Harris P, Chapple IL, et al. Impaired neutrophil extracellular trap formation: a novel defect in the innate immune system of aged individuals. Aging Cell. 2014;13(4):690-698. doi: https://doi.org/10.1111/acel.12222

64. Butcher S, Chahel H, Lord JM. Ageing and the neutrophil: no appetite for killing? Immunology. 2000;100(4):411-416. doi: https://doi.org/10.1046/j.1365-2567.2000.00079.x

65. Butcher SK, Chahal H, Nayak L, et al. Senescence in innate immune responses: reduced neutrophil phagocytic capacity and CD16 expression in elderly humans. J Leukoc Biol. 2001;70:881886.

66. Weiskopf D, Weinberger B, Grubeck-Loebenstein B. The aging of the immune system. Transpl Int. 2009;22(11):1041-1050. doi: https://doi.org/10.1111/j.1432-2277.2009.00927.x

67. Ogawa K, Suzuki K, Okutsu M, Yamazaki K, Shinkai S. The association of elevated reactive oxygen species levels from neutrophils with low-grade inflammation in the elderly. Immun Ageing. 2008;5:13. doi: https://doi.org/10.1186/1742-4933-5-13

68. Sauce D, Dong Y, Campillo-Gimenez L, et al. Reduced oxidative burst by primed neutrophils in the elderly individuals is associated with increased levels of the CD16bright/cd62ldim immunosuppressive subset. J Gerontol A Biol Sci Med Sci. 2016; 72(2):163-172. doi: https://doi.org/10.1093/gerona/glw062 
69. Sadiku P, Willson JA, Dickinson RS, et al. Prolyl hydroxylase 2 inactivation enhances glycogen storage and promotes excessive neutrophilic responses. J Clin Invest. 2017;127(9): 3407-3420. doi: https://doi.org/10.1172/JCI90848

70. Patel JM, Sapey E, Parekh D, et al. Sepsis induces a dysregulated neutrophil phenotype that is associated with increased mortality. Mediators Inflamm. 2018; 2018:4065362. doi: https://doi.org/10.1155/2018/4065362

71. Sapey E, Patel JM, Greenwood H, et al. Simvastatin improves neutrophil function and clinical outcomes in pneumonia: a pilot randomised controlled trial. Am J Respir Crit Care Med. 2019; 200(100):1282-1293.

doi: https://doi.org/10.1164/rccm.201812-23280C

72. Sapey E, Patel JM, Greenwood HL, et al. Pulmonary infections in the elderly lead to impaired neutrophil targeting, which is improved by simvastatin. Am J Respir Crit Care Med. 2017;196(10):1325-1336.

doi: https://doi.org/10.1164/rccm.201704-0814OC

73. Chatta GS, Andrews RG, Rodger E, Schrag M, Hammond WP, Dale DC. Hematopoietic progenitors and aging: alterations in granulocytic precursors and responsiveness to recombinant human G-CSF, GM-CSF, and IL-3. J Gerontol. 1993;48(5): M207212. doi: https://doi.org/10.1093/geronj/48.5.M207

74. Walton GM, Stockley JA, Griffiths D, Sadhra CS, Purvis T, Sapey E. Repurposing treatments to enhance innate immunity. can statins improve neutrophil functions and clinical outcomes in COPD? J Clin Med. 2016; 5(10):89.

doi: https://doi.org/10.3390/jcm5100089

75. Bartlett DB, Fox O, McNulty CL, et al. Habitual physical activity is associated with the maintenance of neutrophil migratory dynamics in healthy older adults. Brain Behav Immun. 2016;56:12-20. doi: https://doi.org/10.1016/j.bbi.2016.02.024

76. Rouhani F, Paone G, Smith NK, Krein P, Barnes P, Brantly ML.Lung neutrophil burden correlates with increased pro-inflammatory cytokines and decreased lung function in individuals with a1antitrypsin deficiency. Chest. 2000;117(5Suppl1):250S-251S. doi: https://doi.org/10.1378/chest.117.5_suppl_1.250S

77. Woolhouse IS. Sputum chemotactic activity in chronic obstructive pulmonary disease: effect of alpha-1 antitrypsin deficiency and the role of leukotriene B4 and interleukin 8 . Thorax. 2002;57(8):709-714.

doi: https://doi.org/10.1136/thorax.57.8.709

78. Sapey E, Bayley D, Ahmad A, Newbold P, Snell N, Stockley RA. Inter-relationships between inflammatory markers in patients with stable COPD with bronchitis: intra-patient and interpatient variability. Thorax. 2008;63(6):493-499. doi: https://doi.org/10.1136/thx.2007.086751
79. Stone H, McNab G, Wood AM, Stockley RA, Sapey E. Variability of sputum inflammatory mediators in COPD and alpha-1 antitrypsin deficiency. Eur Respir J. 2012; 40(3):561-569. doi: https://doi.org/10.1183/09031936.00162811

80. Gane JM, Stockley RA, Sapey E. TNF-alpha autocrine feedback loops in human monocytes: the pro- and anti-inflammatory roles of the TNF-alpha receptors support the concept of selective TNFr-1 blockade in vivo. J Immunol Res. 2016;1079851. doi: https://doi.org/10.1155/2016/1079851

81. Stylianou E. Epigenetics of chronic inflammatory diseases. $J$ Inflamm Res. 2018;12: 1-14.

doi: https://doi.org/10.2147/JIR.S129027

82. Baraldo S, Turato G, Lunardi F, et al. Immune activation in a1-antitrypsin-deficiency emphysema. Beyond the protease-antiprotease paradigm. Am J Respir Crit Care Med. 2014; 191(4):402-409.

doi: https://doi.org/10.1164/rccm.201403-0529OC

83. Sveger T, Piitulainen E, Arborelius Jr M. Lung function in adolescents with a1-antitrypsin deficiency. Acta Paediatr. 1994;83(11):1170-1173.

doi: https://doi.org/10.1111/j.1651-2227.1994.tb 18275.x

84. Piitulainen E, Sveger T. Respiratory symptoms and lung function in young adults with severe alpha(1)-antitrypsin deficiency (PiZZ). Thorax. 2002;57(8):705-708.

doi: https://doi.org/10.1136/thorax.57.8.705

85. Mostafavi B, Diaz S, Piitulainen E, Stoel BC, Wollmer P, Tanash HA. Lung function and CT lung densitometry in 37- to 39-yearold individuals with alpha-1-antitrypsin deficiency. Int J Chron Obstr Pulmon Dis. 2018;13:3689-3698. doi: https://doi.org/10.2147/COPD.S167497

86. Bergin DA, Reeves EP, Meleady P, et al. a-1 Antitrypsin regulates human neutrophil chemotaxis induced by soluble immune complexes and IL-8. J Clinical Invest. 2010;120(12):4236-4250. doi: https://doi.org/10.1172/JCI41196

87. Zen K, Guo Y-L, Li L-M, Bian Z, Zhang C-Y, Liu Y. Cleavage of the $\mathrm{CD} 11 \mathrm{~b}$ extracellular domain by the leukocyte serprocidins is critical for neutrophil detachment during chemotaxis. Blood. 2011;117(18):4885-4894.

doi: https://doi.org/10.1182/blood-2010-05-287722

88. DeLano Frank A, Schmid-Schönbein Geert W. Proteinase activity and receptor cleavage. Hypertension. 2008;52(2):415-423. doi: https://doi.org/10.1161/HYPERTENSIONAHA.107.104356

89. Newby PR, Crossley D, Crisford H, et al. A specific proteinase 3 activity footprint in alpha-1 antitrypsin deficiency. ERJ Open Res. 2019;5(3):00095-02019.

doi: https://doi.org/10.1183/23120541.00095-2019 
90. Carter RI, Ungurs MJ, Pillai A, Mumford RA, Stockley RA. The relationship of the fibrinogen cleavage biomarker aa-Val360 with disease severity and activity in alpha-1 antitrypsin deficiency. Chest. 2015;148(2):382-388.

doi: https://doi.org/10.1378/chest.14-0520

$\overline{\text { 91. Walton G, Butler A, Stockley R, Donnelly L, Sapey E. Impaired }}$ serum opsonisation of non-typeable Haemophilus influenzae in COPD and alpha-1 antitrypsin deficiency. A potential mechanism for reduced bacterial clearance? Eur Respir J. 2017;50(Suppl 61):PA993.

doi: https://doi.org/10.1183/1393003.congress-2017.PA993

92. Frenzel E, Korenbaum E, Hegermann J, et al. Does augmentation with alpha1-antitrypsin affect neutrophil extracellular traps formation? Int J Biol Sci. 2012;8(7):1023-1025. doi: https://doi.org/10.7150/ijbs.4701

93. Hurley K, Lacey N, O’Dwyer CA, et al. Alpha-1 antitrypsin augmentation therapy corrects accelerated neutrophil apoptosis in deficient individuals. J Immunol. 2014;193(8): 3978-3991. doi: https://doi.org/10.4049/jimmunol.1400132

94. Jones HA, Boobis AR, Hamacher K, Coenen HH, Clark JC. PET imaging of pulmonary fibrosis. J Nucl Med. 2003;44:483-484; author reply 484 .

95. Jones NA, Boswell-Smith V, Lever R, Page CP. The effect of selective phosphodiesterase isoenzyme inhibition on neutrophil function in vitro. Pulm Pharmacol Ther. 2005;18(2):93-101. doi: https://doi.org/10.1016/j.pupt.2004.10.001

96. Subramanian DR, Jenkins L, Edgar R, Quraishi N, Stockley RA, Parr DG. Assessment of pulmonary neutrophilic inflammation in emphysema by quantitative positron emission tomography. Am J Respir Crit Care Med. 2012;186(11):1125-1132. doi: https://doi.org/10.1164/rccm.201201-0051OC

97. Carter RI, Mumford RA, Treonze KM, et al. The fibrinogen cleavage product Aa-Val360 specific marker of neutrophil elastase activity in vivo. Thorax. 2011;66(8):686. doi: https://doi.org/10.1136/thx.2010.154690

98. Crossley D, Stockley R, Sapey E. Alpha-1 antitrypsin deficiency and accelerated aging: a new model for an old disease? Drugs Aging. 2019;36:823-840. doi: https://doi.org/10.1007/s40266-019-00684-7

99. Franceschi C, Campisi J. Chronic inflammation (inflammaging) and its potential contribution to age-associated diseases. $J$ Gerontol A Biol Sci Med Sci. 2014;69(Suppl 1):S4-S9. doi: https://doi.org/10.1093/gerona/glu057

100. López-Otín C, Blasco MA, Partridge L, Serrano M, Kroemer G. The hallmarks of aging. Cell. 2013;153(6):1194-1217. doi: https://doi.org/10.1016/j.cell.2013.05.039
101. Renz H, Autenrieth IB, Brandtzæg P, et al. Gene-environment interaction in chronic disease: a European Science Foundation forward look. J Allergy Clin Immunol. 2011;128(6Suppl):S27-S49. doi: https://doi.org/10.1016/j.jaci.2011.09.039

102. Chatterjee A, Stockwell PA, Rodger EJ, et al. Genome-wide DNA methylation map of human neutrophils reveals widespread inter-individual epigenetic variation. Sci Rep. 2015;5:17328. doi: https://doi.org/10.1038/srep17328

103. Stockley JA, Walton GM, Lord JM, Sapey E. Aberrant neutrophil functions in stable chronic obstructive pulmonary disease: the neutrophil as an immunotherapeutic target. Int Immunopharmacol. 2013;17(4):1211-1217. doi: https://doi.org/10.1016/j.intimp.2013.05.035 